\title{
LA RECONVENCIÓN EN LOS LITIGIOS SOBRE CONTRATOS INTERNACIONALES DE TRABAJO. (COMENTARIO A LA STJUE DE 21 DE JUNIO DE 2018, ASUNTO C-1/17, PETRONAS LUBRICANTS ITALY)
}

\author{
THE COUNTER-CLAIM IN LITIGATION ABOUT \\ INTERNATIONAL CONTRACTS OF EMPLOYMENT. \\ (COMMENTARY TO EUCJ JUDGMENT 21 JUNE 2018, \\ CASE C-1/17, PETRONAS LUBRICANTS ITALY)
}

\author{
Ángel Espiniella MenÉndez* \\ Profesor Titular de Derecho Internacional Privado (acreditado a CU) \\ Universidad de Oviedo \\ ORCID ID: 0000-0002-6241-6402
}

Recibido: 17.06.2019 / Aceptado: 05.07.2019

DOI:

\begin{abstract}
Resumen: en su Sentencia de 21 de junio de 2018, en el asunto Petronas Lubricants Italy, el TJUE afirma la viabilidad de una reconvención del empleador contra el trabajador respecto de unos créditos cedidos por otro empleador. La Sentencia tiene aspectos positivos, pues consolida la competencia del juez inicial para una reconvención por razones de economía procesal, incluso cuando el demandante reconvencional sea una parte más fuerte jurídica y económicamente, como es un empleador. En su haber, también, exigir que la reconvención tenga un origen común a la demanda inicial, pues en este foro también persiste el objetivo de buscar resoluciones coherentes.

Entre los aspectos negativos, el Tribunal, al aplicar la doctrina general al caso concreto, legitima una situación abusiva. El demandante reconvencional está utilizando el entramado de sociedades del grupo para diseñar la reconvención y lo hace a través de una cesión de créditos que afecta a la posición procesal del demandado reconvencional. Y ello cuando este demandado reconvencional no participa de dicha cesión (es un acto ajeno) y ni siquiera puede calcular sus efectos, al ser posterior a la interposición de la demanda inicial.
\end{abstract}

Palabras clave: contrato de trabajo, competencia judicial internacional, reconvención. Reglamento "Bruselas I.bis".

Abstract: in its Judgment of 21 June 2018, in case Petronas Lubricants Italy, the EUCJ affirms the viability of a counterclaim by the employer against the worker with respect to credits assigned by another employer. The Judgment has positive aspects, due to it consolidates the jurisdiction of the initial court for a counterclaim for reasons of procedural economy, even when the counterclaimant is a stronger legal and economic party, such as an employer. Also it is positive to require that the counterclaim has a common origin to the initial claim, because this jurisdiction rule keeps the purpose of seeking coherent decisions. Among the negative aspects, the Court, when applies the general doctrine to the specific case, legitimizes

\footnotetext{
* Miembro del Grupo de Investigación Consolidado de Derecho Europeo de la Universidad de Oviedo (EURODERUNIO $\neg$ VI-.IDI/2018/000187). El presente trabajo se adscribe al Proyecto de I+D DER2017-86017-R, "Obstáculos a la movilidad de personas en los nuevos escenarios de la UE", concedido por el Ministerio de Economía, Industria y Competitividad, en los términos del artículo 37 de la Ley 14/2011, de 1 de junio, de la Ciencia, la Tecnología y la Innovación (BOE nº 131, 2-VI-2011).
} 
an abusive situation. The counterclaimant is using the network of group companies in order to design the counterclaim by an assignment of credits that affects the procedural position of the counterclaim defendant. That occurs when this counterclaim defendant does not participate in said assignment (it is an external act) and cannot even calculate its effects, since it is subsequent to the filing of the initial claim.

Keywords: contract of employment. international jurisdiction. counter-claim. Brussels I.a Regulation.

Sumario: I. Presentación. II. La incontrovertida viabilidad de la reconvención en materia laboral: 1. Viabilidad desde una lógica procesal. 2. Viabilidad desde una lógica laboral. III. La exigencia adicional del "origen común" de la reconvención: 1. La necesidad de un origen común. 2. La definición del origen común: ¿un mismo contrato o unos mismos hechos? 3. Consecuencias jurídicas de una hipotética falta de origen común. 4. ¿Quién analiza el origen común: el TJUE o los tribunales nacionales? IV. La discutible proyección al caso: 1. La tesis del Tribunal: la existencia de un origen común. 2. Decálogo para una posible réplica. V. Valoración.

\section{Presentación}

1. En su Sentencia de 21 de junio de 2018, en el asunto C-1/171, el TJUE analiza el caso de un trabajador alto directivo que durante catorce años trabajó para la sociedad Petronas Lubricants Italy. Los siguientes cinco años y, bajo la misma relación contractual, trabajó para PL Poland, sociedad filial controlada al $100 \%$ por la matriz italiana. Finalmente, terminó firmando un contrato de "trabajo paralelo de duración determinada" con dicha sociedad filial polaca. No queda claro si el primer contrato con la matriz quedo en suspenso o si fue simultaneado. Pero sí que, trece años después, recibe sendas notificaciones de ambas sociedades, informándole la sociedad matriz de un "despido por causa justificada" y la sociedad filial de la "extinción de su relación laboral"2.

En este escenario el trabajador presenta una demanda por despido improcedente respecto del primer contrato contra la sociedad matriz italiana ante los tribunales italianos, además de pedir una reparación por el daño moral sufrido por el carácter injurioso del despido. No en vano, los motivos del despido se basaban en reembolsos indebidos por supuestos desplazamientos, por compensaciones sustitutivas que no procedían y por mala fe en la aplicación del cambio de divisas. La sociedad matriz demandada comparece y contesta a la demanda, al tiempo que presenta una reconvención para el reembolso de los gastos que de forma improcedente había cobrado el trabajador, por un valor de más de 140.000 euros.

2. La cuestión discutida es si el tribunal italiano es competente para esa reconvención. En principio, el Reglamento "Bruselas I", y su actual versión ("Bruselas I.bis") que se pronuncia en los mismos términos, permite que el tribunal que conoce de la demanda inicial conozca de la reconvención del demandado ${ }^{3}$. Pero el problema en el caso es que el demandado reconviene en referencia no a sus propios créditos, sino a créditos de su sociedad filial polaca, que no está demandada en el pleito. Estos créditos habían sido cedidos con posterioridad a presentarse la demanda inicial. Por ello, el demandante inicial entiende que esa reconvención no procede por falta de competencia de los tribunales italianos, pues los créditos no pertenecen al empleador italiano.

Así las cosas, el Tribunale di Torino condena a la sociedad matriz demandada y declinó la competencia respecto de la reconvención, entendiendo que esta reclamación debía presentarse ante los tribunales polacos ${ }^{4}$. La competencia para la reconvención solo afecta a créditos de la "esfera jurídica" del demandado y no de terceros que los cede. En apelación, la Corte d'apello formula cuestión prejudicial al respecto.

\footnotetext{
${ }^{1}$ ECLI:EU:C:2018:478.

${ }^{2}$ Sobre los problemas en contratos internacionales simultáneos en el marco de un grupo de empresas, vid. G. PALAo MorenO, Los grupos de empresas multinacionales y el contrato individual de trabajo, Valencia, Tirant lo Blanch, 2000, pp. 234 y ss.; P. JuÁREZ PÉREZ, Las relaciones laborales en los grupos internacionales de sociedades, Granada, Comares, 2000, pp. 93 y ss.

${ }^{3}$ Tal y como recuerda el Abogado General, la demanda del trabajador fue presentada antes del 10 de enero de 2015. El Reglamento "Bruselas I" fue derogado por el "Bruselas I.bis" pero solo para las acciones judiciales ejercitadas a partir del 10 de enero de 2015.

${ }^{4}$ Cf. apartado 14.
} 
3. En este contexto, y con carácter preliminar, conviene precisar que el tribunal italiano consideró que el domicilio del trabajador estaba en Polonia y no en Italia ${ }^{5}$. La cuestión es relevante porque, de haber estado en Italia, el problema práctico habría desaparecido casi totalmente. En efecto, en tal caso, los tribunales italianos habrían sido competentes en cualquier escenario: vía reconvención si la cuestión se considera vinculada a la demanda inicial respecto del contrato de la matriz; vía, domicilio del demandado si la demanda se considerara propia del contrato de trabajo de la filial y totalmente ajena a la reconvención del Reglamento "Bruselas I".

Hecha esta aclaración, en las próximas líneas se abordará la viabilidad de la reconvención en materia laboral (II), la exigencia para ello de un origen común entre las distintas pretensiones (III) y su proyección en el caso concreto (IV). Si bien la doctrina general que sienta la Sentencia parece sólida, es precisamente en su aplicación al caso donde existen más dudas.

\section{La incontrovertida viabilidad de la reconvención en materia laboral}

\section{Viabilidad desde una lógica procesal}

4. En el apartado 29 de la Sentencia, el Tribunal se refiere a que no existe un concepto de reconvención en la sección de trabajadores. Para remediarlo, curiosamente remite al foro general de la reconvención, que tampoco tiene una definición uniforme del concepto. Sorprende, no obstante, que, cuando parece que el Tribunal va a definir este concepto, lo que hace en realidad es señalar los objetivos de las normas de competencia. Más preciso es el Abogado General que constata que no se ha presentado un motivo de defensa por el demandado, sino la solicitud de una condena distinta ${ }^{6}$.

5. Precisamente estos objetivos son enunciados de forma positiva y negativa. De forma positiva, la competencia del juez inicial para la reconvención se basa en una buena administración de justicia, para resolver en un mismo procedimiento y ante un mismo juez "pretensiones recíprocas que tienen un origen común". Formulados en sentido negativo, se trata de evitar "múltiples y superfluos procedimientos". El concepto de "múltiples" parece claro: desdoblar la competencia e impedir la acumulación implica al menos dos tribunales competentes, probablemente de distintos Estados, y distintas representaciones legales. El concepto de "superfluos" ya puede ser más discutible, pues no es tanto que un segundo procedimiento no cumpla su función, sino más bien que existen mecanismos más expeditivos para resolverlos por medio de una acumulación procesal ${ }^{8}$.

Al margen de estas precisiones más o menos menores, debe coincidirse con los objetivos destacados por el Tribunal. Ciertamente, podrían señalarse razones de economía procesal para permitir la reconvención ante el tribunal inicial, pues, habiendo un litigio en el que las partes están debidamente representadas, parece sostenible que el mismo tribunal conozca de otras reclamaciones.

\section{Viabilidad desde una lógica laboral}

6. El Tribunal recuerda que el Reglamento "Bruselas I", en su artículo 20, apartado 2 (actual 22), perteneciente a la Sección sobre contrato individual de trabajo, atribuye competencia judicial internacional al órgano que conoce de la demanda inicial ${ }^{9}$. Ello es un acierto pues la sección de trabajadores tiene carácter exhaustivo y no permite fundamentar la competencia en normas contenidas en otra sección, con

\footnotetext{
${ }^{5}$ Cf. apartado 16.

${ }^{6}$ Cf. apartado 22. Vid. la STJCE 13 julio 1995, Danvarn Production, C-341/93, EU:C:1995:239, apartados 15 y 18.

7 Vid. A. L. Calvo Caravaca y J. Carrascosa González, "Competencia judicial internacional y Derecho de los negocios internacionales. El Reglamento 1215/2012 "Bruselas I.bis" de 12 de diciembre de 2000", Derecho Internacional Privado, vol. II, $18^{\text {a }}$ edición, Granada, Comares, 2018, pp. 698-842, p. 800.

${ }^{8}$ Vid. STJUE 12 octubre 2016, Kostanjevec, C 185/15, EU:C:2016:763, apartado 37.

9 Vid. M. Gardeñes Santiago, "Reconvención y contrato internacional de trabajo", La Ley UE, nº 62, 2018, núm. II, sobre las dudas en torno a si estos contratos podían calificarse como de trabajo.
} 
la excepción de litigios sobre sucursales y sobre litisconsorcios pasivos de empleadores (en este caso, solo en la segunda versión del Reglamento $)^{10}$. Así pues, de no existir esa previsión específica, no cabría la competencia para la reconvención por imposibilidad de acudir a otras secciones y, en particular, al artículo 6.3 del Reglamento "Bruselas I" y al artículo 8.3 de la versión refundida.

7. La viabilidad de la reconvención formulada por un empleador no parece ser contraria a los objetivos de la regulación sobre contrato individual de trabajo, básicamente proteger al trabajador como parte más débil desde una perspectiva jurídica y económica ${ }^{11}$. Esta protección se traduce, en palabras del Tribunal, en la posibilidad de demandar al empleador ante un órgano jurisdiccional "más cercano a sus intereses", reconociéndole "legitimación activa"12. Hay en estas afirmaciones una idea correcta, pero con alguna imprecisión. La primera, la de incluir en este objetivo la posibilidad de demandar en el Estado del domicilio del empleador demandado, que responde más a una idea general de protección procesal del demandado que a la protección del trabajador demandante. El verdadero foro de protección para el trabajador es la alternativa de poder demandar en el lugar donde se prestan habitualmente los servicios. La segunda imprecisión sería la de confundir "competencia judicial internacional" con "legitimación activa", por lo menos en la versión en castellano de la Sentencia. Ciertamente, el Reglamento "Bruselas I" se refiere a la competencia internacional de tribunales de Estados miembros, y no a la legitimación activa. Esta cuestión, entendida como interés legítimo para ocupar la posición procesal de demandante o demandado, queda determinada por la ley rectora del contrato, la ley del fondo. La última imprecisión, y quizá la más grave, es que el Tribunal se queda en la superficie sobre los objetivos de la sección de trabajadores, y no entra en la cuestión de mayor interés: si la reconvención la puede presentar el empleador, como parte fuerte en la relación laboral.

A este respecto, más preciso se muestra el Abogado General en el apartado 23 de sus Conclusiones. Su posicionamiento claramente favorable a que la parte fuerte puede hacer uso del foro reconvencional debe considerarse correcto. La interpretación literal del precepto no admite discusión ${ }^{13}$. En ningún momento se restringe este foro al trabajador y ello por una razón fundamental: el objetivo de buena administración de justicia parece prevalecer en este caso sobre la protección al trabajador. El Abogado General añade un argumento histórico ${ }^{14}$. La creación de una sección específica de trabajadores en el Reglamento "Bruselas I" no pretendía un cambio sustancial en el fondo respecto de los precedentes, sino una sistematización en una sección específica como ocurría con consumo y seguros $^{15}$. De ello se puede desprender la misma interpretación del foro reconvencional que existía en los precedentes hasta la fecha con carácter general y que en modo alguno vetaban su utilización por el empleador.

Admitida la procedencia de la reconvención por el empleador, debe señalarse que, en la práctica, esta juega mayormente cuando el trabajador demanda al empleador en su domicilio y este aprovecha dicha estrategia para reconvenir en su propio domicilio. Tiene menor incidencia cuando el trabajador demanda allí donde trabaja de forma habitual. En ese caso, normalmente, el trabajador suele tener su domicilio en ese Estado, por lo que la posibilidad de que el empleador reconvenga en este Estado estaría en la mayoría de los casos amparada por el propio foro general del domicilio del trabajador demandado. El foro por reconvención apenas aportaría nada, más allá de delimitar la competencia interna.

\footnotetext{
${ }^{10}$ Cf. apartado 25; y STJUE de 22 de mayo de 2008, Glaxosmithkline, C 462/06, EU:C:2008:299, apartado 22.

${ }^{11} C f$. apartado 23. Vid. Sentencias anteriores como la de 14 de septiembre de 2017, Nogueira y otros, C 168/16 y C 169/16, EU:C:2017:688.

${ }^{12}$ Cf. apartado 24.

${ }^{13}$ Vid. STJCE 22 mayo 2008, Glaxosmithkline, antes citada, apartado 29. M. GARDEÑES SANTIAGO destaca, además, la propia ubicación de esta regla en el precepto sobre demandas del empleador contra el trabajador (loc. cit., núm. IV).

${ }^{14} \mathrm{Cf}$. apartado 27.

15 Vid. la exposición de motivos de la Propuesta de la Comisión de Reglamento (CE) del Consejo relativo a la competencia judicial, al reconocimiento y a la ejecución de resoluciones judiciales en materia civil y mercantil [COM(1999) 348 final].
} 


\section{La exigencia adicional del "origen común” de la reconvención}

\section{La necesidad de un origen común}

8. Analizada la pertinencia de la reconvención por motivos procesales y contractuales, debe analizarse el aspecto más espinoso de la Sentencia: la exigencia de un origen común entre la demanda inicial y la reconvención.

En este sentido, el fundamento de la competencia para la reconvención es que exista un único juez para pretensiones recíprocas, siendo, además, necesario que tengan un origen común. Ello no se señala en el artículo 20.2 (actual 22.2) en materia laboral, aunque sí está previsto en el artículo 6.3 (actual 8.3). La relación entre ambos preceptos podría hacerse de dos formas distintas:

Primera, una interpretación en términos disyuntivos, según la cual, si el precepto sobre contrato de trabajo no contempla los requisitos del foro general, es porque, a diferencia de este, no son exigibles ${ }^{16}$.

Segunda, una interpretación sistemática, conforme a la que los requisitos del foro general también son extensibles al foro especial.

El Tribunal claramente se inclina por esta última con acierto ${ }^{17}$. Efectivamente, no se trata de que la reconvención en materia laboral se aparte de la reconvención en el ámbito general. Los argumentos de buena administración de justicia se ven sustentados también por razones de conexidad entre reclamaciones, pues qué mejor que un mismo tribunal conozca de dos demandas que, de llevarse a tribunales distintos, podrían llevar a soluciones incoherentes o inconsistentes ${ }^{18}$. Piénsese, por ejemplo, que unos mismos hechos sean valorados de forma distinta por dos tribunales. La suma de estos dos objetivos, economía procesal y coherencia, pueden llevarnos a una conclusión no explicitada en el Reglamento en materia laboral, pero de especial interés para el caso: entre la demanda inicial y la reconvención tiene que haber cierta relación. No se trata de llevar a un mismo tribunal cualquier controversia entre las partes, sino solo las controversias relacionadas con un mismo contrato o con unos mismos hechos.

\section{La definición del origen común: ¿un mismo contrato o unos mismos hechos?}

9. Esta interpretación sistemática entre el artículo 6.3 y el 20.2 del Reglamento "Bruselas I.bis" (actuales 8.3 y 22.2) hace que el Tribunal busque el origen común en un mismo contrato o en unos mismos hechos. Y lo hace conforme a una interpretación uniforme ajena a las distintas legislaciones nacionales ${ }^{19}$.

Aquí ya es donde caben algunas discrepancias. Hay dos cuestiones previas que sí deben quedar determinadas por las legislaciones nacionales. Por un lado, la legitimación activa de un demandado para presentar la reconvención. Debería ser la ley polaca, como ley rectora del crédito cedido, la que determinara si el cesionario tiene legitimación para dirigirse contra el deudor, el trabajador demandado por reconvención. Por otro lado, la figura de la reconvención debe estar reconocida en los ordenamientos procesales nacionales, en el caso, en la legislación procesal italiana. Este es un presupuesto procesal para el ejercicio de la reconvención. El Reglamento "Bruselas I" no atribuye un derecho a presentar reconvención, solo facilita la competencia judicial internacional cuando esta es posible según la ley del foro. Por poner un ejemplo, si la ley del foro no reconoce la reconvención o considera que el juez inicial no tiene competencia material o funcional para conocer de ella, no parece posible esta reconvención.

\footnotetext{
16 Vid., planteando el problema, P. JuÁrez PÉREz, Orden social y litigios internacionales: competencia judicial, Granada, Comares, 2002, p. 115.

${ }^{17} C f$. apartados 29 y 30. En el mismo sentido, vid. el apartado 29 de las Conclusiones del Abogado General. Entre las Sentencias anteriores, destaca la de 22 de mayo de 2008, Glaxosmithkline, antes citada, apartado 22. En la doctrina, vid. M. Gardeñes Santiago, loc. cit., núm. III, sobre las dudas en torno a si estos contratos podían calificarse como de trabajo.

${ }^{18} \mathrm{Vid}$. apartado 26 y 32 de las Conclusiones del Abogado General. Recuerda que, en el informe del Sr. P. Jenard, sobre el Convenio de Bruselas (DO 1979, C 59), se precisó que la reconvención deberá ser una demanda conexa a la demanda principal, tomando como referencia el Código judicial belga. Un buen ejemplo se encuentra en la STJUE 12 octubre 2016, Kostanjevec, ya citada, apartado 38, donde existe un origen común entre la demanda inicial relacionada con un contrato y la reconvención sobre el enriquecimiento injusto relacionado con ese contrato.

19 Vid., en el mismo sentido, el apartado 30 de las Conclusiones del Abogado General.
} 
Así pues, si la legislación polaca no diera tal legitimación o la legislación italiana no contemplara la figura de la reconvención, directamente no habría problema de competencia internacional que tratar. O, expuesto de otra forma, el problema de la competencia judicial internacional solo debería plantearse si cabe reconvención porque el demandado tiene legitimación reconvencional y la ley del foro admite el juego de esta reconvención.

10. Además del problema señalado, ha quedado constatado que el trabajador firma dos contratos paralelos, uno con la sociedad matriz italiana, otro con la filial polaca. En ningún momento ha existido una confusión entre contratos ni entre las relaciones laborales ${ }^{20}$. Descartado que exista un mismo contrato como origen común de la reconvención, el Tribunal sí concluye que existe una misma situación de hecho ${ }^{21}$. La cuestión más interesante en este punto es la alternatividad con la que interpreta "mismo contrato o misma situación de hecho". De nuevo cabrían dos interpretaciones:

Una disyuntiva, relativa a que la reconvención basada en un mismo contrato jugaría en materias contractuales y la reconvención basada en los mismos hechos jugaría para materias no contractuales.

La otra interpretación, que claramente asume el Tribunal, es en clave cumulativa, esto es: el origen común de las pretensiones puede basarse en unos mismos hechos aunque no lo esté en un mismo contrato $^{22}$. El Abogado General explicita perfectamente este parecer en el apartado 41 de las Conclusiones. Señala que la reconvención no debe limitarse a un mismo marco contractual, cuando existe identidad de hechos y la necesidad de que un mismo juez se pronuncie sobre la misma cuestión en interés de la buena administración de justicia y la evitación de resoluciones inconciliables.

11. A pesar de lo expuesto, no puede asumirse claramente este posicionamiento a favor de que, existiendo varios contratos de trabajo, es suficiente la constatación de una misma situación fáctica. En efecto, unos mismos hechos y unas mismas circunstancias pueden tener múltiples consecuencias jurídicas en distintos contratos ${ }^{23}$. Esas múltiples consecuencias pueden deberse a la aplicación de leyes distintas a los distintos contratos, en el caso, la legislación italiana al contrato con la empleadora italiana, y la polaca al contrato con la empleadora polaca. Esta cuestión se despacha lacónicamente por el Abogado General en el apartado 40 de sus Conclusiones con una simple diferenciación entre competencia judicial y ley aplicable al fondo. Esa autonomía no se pone en duda, pero se obvia que ello demuestra que unos mismos hechos pueden tener ramificaciones jurídicas distintas.

Es más, respecto de estos contratos no ha quedada acreditada una relación causal de dependencia. La extinción de uno de ellos no tendría por qué afectar al otro, como tampoco la invalidez de uno condiciona la del otro. La imputación de hechos vinculada a irregularidades en uno de los contratos tampoco tendría que afectar al otro contrato, si en su cumplimiento no han existido las mismas o parecidas irregularidades. Al margen de esta autonomía contractual, hay un dato que obvia el Tribunal y que debe ser tenido en cuenta: la reconvención regulada en una sección denominada "contrato individual del trabajo" no puede minusvalorar la existencia de distintos contratos, ni poner esta a la misma altura que la existencia de una misma situación.

\section{Consecuencias jurídicas de una hipotética falta de origen común}

12. La existencia de un origen común entre demanda inicial y reconvención haría competente al juez inicial para conocer de la reconvención y así lo considera el Tribunal de Justicia. Pero, desde el momento en el que se exige ese requisito adicional, cabe plantearse qué ocurriría si, al margen del caso, no existe ese origen común. En principio, no habría competencia judicial internacional del juez inicial.

\footnotetext{
${ }^{20}$ Sobre esta problemática, vid. H. Muir Watt, “Article 8”, en U. Magnus y M. Mankowski, ECPIL. Brussels Ibis Regulation, Colonia, O. Schmidt, 2016, pp. 369-405, p. 401.

${ }^{21}$ Cf. apartado 31 .

${ }^{22}$ En el mismo sentido, vid. apartado 42 de las Conclusiones del Abogado General.

${ }^{23}$ En sentido contrario, vid. el apartado 37 de las Conclusiones del Abogado General, señalando que los mismos hechos afectan a las dos sociedades indistintamente.
} 
Ahora bien, no parece que el juez de oficio deba controlar la falta de competencia, salvo que la materia de la reconvención se corresponda con una competencia exclusiva ${ }^{24}$. Al margen de este caso, no haría falta ese control de competencia de oficio porque ambas partes están personadas en el proceso inicial y este es un dato importante. Falta, pues, el presupuesto de abstenerse de oficio si el demandado no comparece y no existe ningún fundamento de competencia ${ }^{25}$.

13. Así las cosas, el control de la competencia solo se haría a instancia de parte, en este caso, del demandante inicial, ahora demandado por reconvención. Este podrá impugnar la competencia para la reconvención y ello se hará de conformidad con la legislación procesal nacional. Esa legislación tiene que tener algún tipo de mecanismo que permita preservar el efecto útil del Reglamento y la posibilidad de controlar la competencia en los términos del Reglamento: el "origen común" entre la demanda inicial y la reconvención. Repárese en que este trámite es obligado porque, al margen del caso concreto y de posibles discrepancias con el fallo, el Tribunal deja claro que, en el Reglamento "Bruselas I", la reconvención no juega automáticamente.

14. La otra opción del demandado por reconvención es que no impugne la competencia, por lo que el tribunal inicial podría conocer de esa contrademanda que no tenga el mismo origen que la demanda inicial. No existe ningún inconveniente a que la sumisión tácita pueda jugar en estos casos. En cualquier caso, parece necesario que, en la actual versión del Reglamento "Bruselas I.bis", el tribunal informe a la parte débil demandada por reconvención, en este caso el trabajador, de las consecuencias que tendría la no impugnación de la competencia respecto una reconvención sin origen común a la demanda inicial ${ }^{26}$.

\section{4. ¿Quién analiza el origen común: el TJUE o los tribunales nacionales?}

15. Al margen de la tensión entre una interpretación disyuntiva (si no se basa en un mismo contrato, es irrelevante la misma situación) y una interpretación acumulativa (aunque no haya un mismo contrato, basta una misma situación), otro aspecto relevante es cómo se constata la presencia de una misma situación fáctica. Dos cuestiones son de especial interés: quién debe valorar esa situación y si esa situación está presente en el caso.

Respecto de quién debe valorar ese mismo origen, existe una discrepancia entre la Sala Tercera del Tribunal de Justicia, que en esta Sentencia lo considera incluido en el ámbito de su competencia de interpretación uniforme, y el Abogado General, que opina que deben ser los órganos jurisdiccionales nacionales, en concordancia con lo que pocos días antes había señalado la Sala Octava del Tribunal27. En este sentido, hace ya algún tiempo que el Tribunal de Justicia ha transitado de la mera interpretación de normas a determinar si los supuestos de hecho que le llegan se subsumen o no en una determinada norma. Una posición quizá flexible, pero con un efecto expansivo de la interpretación uniforme especialmente útil, si se asume que el Tribunal se pronuncia sobre supuestos estándar. Debe quedar los órganos jurisdiccionales la valoración probatoria de los hechos y su encaje en el estándar perfilado por el Tribunal de Justicia.

Así las cosas, la Sala Tercera del Tribunal de Justicia se atreve a señalar que, "en una situación como la controvertida en el litigio principal", la situación fáctica está avalada por la pertenencia a un mismo grupo de las dos sociedades empleadoras. También, por el hecho de que la extinción de los contratos se produjo el mismo día y con causas más o menos similares.

\footnotetext{
${ }^{24}$ Artículo 25 del Reglamento "Bruselas I", actual artículo 27.

${ }^{25}$ Artículo 26 del Reglamento "Bruselas I", actual artículo 28.

${ }^{26}$ Artículo 26, apartado 2.

${ }^{27} C f$. apartado 42 de las Conclusiones del Abogado General. En este sentido, parecía interpretarse el apartado 23 de la STJUE (Sala Octava) 31 mayo 2018, Nothartová, C-306/17, EU:C:2018:360, cuando señalaba que "en una situación en la que un órgano jurisdiccional conoce de una o de varias pretensiones invocadas a título reconvencional, incumbe a este órgano jurisdiccional apreciar en qué medida esas pretensiones comparten un origen común con la demanda inicial, de modo que les resulta de aplicación el artículo 8, punto 3, del Reglamento $n^{\circ} 1215 / 2012$ ". Al respecto, vid. J. C. Fernández RozAS y S. SÁnchez Lorenzo, Derecho Internacional Privado, 10 a ed., Cizur Menor, Civitas/Thomson Reuters, 2018, p. 94.
} 
16. Estos hechos precisan de un análisis detallado. En efecto, es indiscutible la relación entre las dos sociedades empleadoras, pues una de ellas, la compañía italiana, es la propietaria del $100 \%$ del capital social de la otra empleadora, la sociedad polaca. Así pues, existe una evidente relación societaria y empresarial entre los dos empleadores. Baste comprobar que la notificación de despido y de extinción de sendos contratos se realiza el mismo día, evidenciando que las sociedades actúan de forma coordinada y de común acuerdo.

Pero esta definición de una misma situación desde una perspectiva subjetiva necesita consolidarse desde la perspectiva objetiva de los hechos. Las causas, los hechos y las circunstancias son básicamente las mismas: liquidación irregular de indemnizaciones por desplazamiento y por sustitución de vacaciones.

A sensu contrario, faltando algunos de los requisitos subjetivos u objetivos, ya no cabría observar una misma situación. De este modo, si las causas y circunstancias de los despidos son por hechos más o menos similares, pero entre los empleadores existe una total independencia sin una relación societaria o empresarial entre ellos, no cabría la reconvención con base en una misma situación fáctica. Por otro lado, si los despidos en sendas relaciones se basan en causas distintas y por hechos y circunstancias separables, no cabe concluir la existencia de una misma situación. Y ello aunque existiera una relación societaria o empresarial entre estas empresas empleadoras.

\section{La discutible proyección al caso}

\section{La tesis del Tribunal: la existencia de un origen común}

17. En este contexto, el Tribunal de Justicia acaba afirmando la viabilidad de la reconvención en un caso como el presentado, porque existe un origen común entre la demanda inicial y la reconvención. No afecta a esta conclusión que la reconvención sea fruto de la cesión de créditos de otro empleador al empleador demandado, cesión materializada con posterioridad a la demanda inicial. Varios son los argumentos que se pueden deducir de una argumentación no muy sistematizada:

i) Argumento literal: básicamente de lege lata no hay ninguna duda sobre que se trata de una reconvención en materia de trabajadores.

ii) Argumento sistemático: el riesgo de que la demanda reconvencional sea una forma de que el demandante por reconvención ataque en su propio domicilio (o de otra sociedad del grupo) es inherente al sistema de "Bruselas". En efecto, si el foro general es el del domicilio del demandado, la admisibilidad general de la reconvención se convierte en la posibilidad de contraatacar en el propio domicilio.

iii) Argumento procesal: aun siendo verdad que en el momento de la demanda inicial el actor desconoce la estrategia del demandado, sí que puede conocer que asume un riesgo de contrademanda ante ese tribunal. La clave es determinar cuál puede ser el alcance de esa contrademanda y para ello es necesaria cierta vinculación entre la demanda inicial y la reconvención.

iv) Argumento de intereses: la posibilidad de presentar reconvención ante el tribunal que conoce de la acción inicial consigue restablecer el equilibrio procesal entre las partes. Si inicialmente el demandante se ve protegido, al poder utilizar normas favorables a sus intereses, el demandado se ve mínimamente compensado a posteriori de forma que puede contraatacar en el mismo tribunal por economía procesal. De especial interés resultan las afirmaciones sobre la reconvención en los apartados 27 y 28 de la Sentencia. En ellos se destaca cómo el Reglamento favorece una estrategia acorde con los intereses del trabajador demandante. Precisamente, por ello, parece razonable que después pueda convertirse en demandado en ese tribunal. Se cumple el objetivo de dar preferencia al trabajador.

v) Argumento práctico: destacado especialmente por el Abogado General en el apartado 35 de sus Conclusiones, entiende que la interconexión de relaciones laborales es muy frecuente, 
coexistiendo contratos inicial y contratos locales en el marco de un desplazamiento ${ }^{28}$. En esos casos, debe afirmarse la existencia de un origen común entre la demanda inicial y la reconvención.

\section{Decálogo para una posible réplica}

18. Como se ha señalado, en el presente caso, el Tribunal entiende que las pretensiones recíprocas tienen un origen común, dada la concurrencia de este presupuesto subjetivo (ambas empleadoras pertenecen al mismo grupo) y objetivo (se basan en unos mismos hechos). Sin embargo, el fallo de la Sentencia es rebatible, como en su momento defendió la Comisión ${ }^{29}$. Varios son los argumentos:

i) Un argumento literal: la reconvención en materia laboral se prevé en una sección denominada "contrato individual de trabajo" por lo que parece que no puede ser utilizada respecto de "otro" contrato distinto. Si los contratos son individualizables, y en este caso parece que lo son, deben tratarse por separado.

ii) Un argumento histórico: la sección nacida para el contrato individual de trabajo buscaba evitar la inclusión de relaciones colectivas. Parecía pensado para no regular litigios interpuestos conjuntamente por dos o más trabajadores en atención a sus respectivos contratos. Pero no hay razón para que no juegue en contra de dos empleadores existiendo dos relaciones laborales respecto de un mismo trabajador.

iii) La lógica de la cesión de créditos: hay un principio consolidado en la cesión de créditos según el cual las relaciones internas entre cedente y cesionario no pueden afectar al deudor, ni a su posición originaria en la relación. Ello es así porque este deudor es un outsider a la cesión, lo que le puede generar cierta imprevisibilidad ${ }^{30}$. Pues bien, en este caso, la cesión afecta sobremanera a la posición procesal del deudor. Baste reparar en que, si no hubiera habido esa cesión, la reconvención sería inviable. El demandado no tendría legitimación activa para reconvenir por esos créditos.

iv) Un argumento de coherencia "horizontal" 31 : el principio de que las relaciones entre cesionario y cedente no pueden afectar al deudor está recogido en el ámbito de la ley aplicable del Reglamento "Roma I". Pero podría entenderse que es un principio sistemático del Derecho internacional privado europeo, incluidas sus normas de competencia judicial internacional. Así, es admisible que el subrogante se coloque en la posición del subrogado, pero no la inversa, que es lo que concurre en el caso: que el subrogado se coloque indirectamente en la posición del subrogante.

v) Un argumento de alcance de la competencia judicial internacional: la competencia inicial en el ámbito del Reglamento "Bruselas I" se articula esencialmente sobre el lugar de prestación habitual del trabajo en el marco de una relación contractual. Parece lógico que cualquier reconvención se base precisamente en ese contrato, lo que no ocurre en el caso pues los créditos se basan en otro contrato, que se ejecuta en Polonia.

vi) Un argumento de contexto procesal de la reconvención: muy vinculado al anterior, el de la reconvención es un foro dependiente de un foro inicial del que trae su causa. En este caso, la interpretación del Tribunal rompe la relación causa-efecto. Si inicialmente el tribunal es competente por ejecutarse el contrato en Italia o por hallarse el domicilio del demandado en dicho Estado, las reclamaciones por reconvención tienen que relacionarse con ese contrato ejecutado en Italia. No parece oportuno que un tribunal declarado competente para cuestiones de un contrato, conozca por reconvención de otro contrato.

${ }^{28}$ Vid., por ejemplo, STJCE 10 abril 2003, Pugliese, C-437/00, EU:C:2003:219; y STJUE de 10 de septiembre de 2015, Holterman, C-47/14, EU:C:2015:574.

${ }^{29} \mathrm{Cf}$. apartado 33 de las Conclusiones del Abogado General.

${ }^{30}$ Esta era la posición de la Comisión, $c f$. apartado 38 de las Conclusiones del Abogado General.

${ }^{31}$ Retomando la terminología de S. SÁnChEZ LoREnzo en "El principio de coherencia en el Derecho internacional privado europeo", REDI, vol. 70 (2018-2), pp. 17-47, esp. pp. 21 y ss. 
vii) Un argumento de desprotección del trabajador: ligado a lo anterior, conviene llamar la atención sobre que, al margen de eventuales litisconsorcios pasivos, el tribunal italiano no sería competente para conocer de cualquier reclamación individual relacionada con el contrato de Polonia presentada por el trabajador. Ni el domicilio del demandado se halla en ese Estado, ni ese contrato se ejecuta en territorio italiano. Sorprende, por tanto, que un tribunal conozca por reconvención de una materia, respecto de la cual la contraparte, el trabajador, individualmente y fuera de los litisconsorcios, nunca podría presentar la demanda ante ese tribunal.

Ello demuestra que la cesión en el marco de un grupo de sociedades pone el entramado societario a disposición de estrategias procesales de su conveniencia. Cosa que a la inversa no ocurre con el trabajador, que no puede tener ese diseño de estrategias con base en cesiones. No es realista pensar en un trabajador cediendo sus créditos a otro trabajador demandado para que los presente por reconvención. La conclusión es que el desequilibrio económico y jurídico en perjuicio del trabajador se ve claramente agravado, siendo contrario al objetivo de la normativa.

viii) Un argumento de abuso procesal: como ya se ha destacado, en el presente caso, por la vía de la cesión, el cedente se beneficia indirectamente de un foro que en ningún caso le correspondería. Ni él ha sido demandado, ni son los tribunales de su domicilio, ni el contrato controvertido en cuestión se ejecuta en Italia. La defensa que hace el Abogado General en el apartado 39 de esta consecuencia no es convincente. Señala que la reconvención ante un tribunal italiano es fruto de la opción del trabajador de demandar en el domicilio del demandado y esa opción no debe tener consecuencias en las posibilidades de una reconvención. El argumento sería sostenible si la reconvención la presentara la sociedad italiana en relación con su contrato, pero es mucho más discutible cuando lo hace en referencia a otro contrato.

Este abuso se confirma por dos extremos. Por un lado, el cesionario no es un tercero totalmente independiente, sino la propia sociedad matriz dominante del grupo de empresas. Cedente y cesionario están actuando de común acuerdo para diseñar su estrategia procesal contra el trabajador. En otras palabras, el entramado de sociedades sirve para, con una simple cesión, aplicar medidas de retorsión a la demanda inicial del trabajador.

Por otro lado, el abuso se ve corroborado por el hecho de que la cesión se produce una vez interpuesta la demanda por el trabajador; para ser exactos, dos días antes de la personación del demandado ${ }^{32}$. El foro reconvencional acaba siendo una trampa porque, en el momento de presentarse la demanda inicial, el demandante parte débil desconoce totalmente cuál puede ser la estrategia del demandado. Es curioso en este sentido el apartado 33 de la Sentencia, que, en la versión en castellano, apenas se entiende ${ }^{33}$. Señala que no es "pertinente" el que la cesión de créditos sea posterior a la demanda, porque el empresario no sabe de antemano dónde va a ser demandado. Ciertamente, la idea es precisamente la contraria: si la cesión se hace después de la demanda inicial, es porque en ese momento cedente y cesionario ya pueden calcular fácilmente dónde se concretaría la reconvención y ello es especialmente grave. Tan grave como que, en el momento de presentación de la demanda, el trabajador demandante no puede calcular de ninguna forma esa reconvención. Deberían aplicarse principios similares a los de la "perpetuación de la jurisdicción", según la cual la fecha crítica a considerar para los hechos de la litis es el momento de interposición de la demanda.

ix) Un argumento de economía procesal relativizado: podría pensarse que la falta de competencia del juez original para la reconvención, en el fondo, desprotege al trabajador inicialmente demandante, que se va a haber atacado en otro proceso, probablemente con la necesidad de designar abogado y procurador. La duplicidad de procesos perjudicaría al trabajador. Sin embargo, esta lectura no es del todo exacta. No se trata de que el juez

\footnotetext{
${ }^{32} C f$. apartados 13 y 14 de las Conclusiones del Abogado General.

${ }^{33}$ Más claro es el Abogado General en el apartado 41 de sus Conclusiones, que simple resta importancia a que la demanda se haya prestado a posteriori.
} 
inicial no conozca del caso en perjuicio del trabajador, sino de que sea precisamente el trabajador el que decida aceptar o no la competencia del juez inicial. Se trata de no imponer la competencia por reconvención y de supeditarla a la voluntad del trabajador inicialmente demandante, a través de una sumisión tácita por la que muestre su conformidad.

x) Un argumento de igualdad de armas procesales: el Tribunal no entra en una cuestión previa y que podría tener su interés: si el trabajador podría tener igualdad de armas que los empleadores, permitiéndose demandar a ambos empleadores en el domicilio de cualquiera de ellos. Conviene distinguir dos escenarios. En la primera versión del Reglamento "Bruselas I", no parece posible codemandar a ambos empleadores ${ }^{34}$. Parece desigual, entonces, permitir que la sociedad polaca pueda reconvenir indirectamente y de facto por una mera cesión a una sociedad del mismo grupo. En el texto refundido del Reglamento "Bruselas I.bis", la cuestión sí está resuelta favorablemente pro futuro, de forma que el trabajador sí podría haber demandado a ambos empleadores por situaciones conexas ante el tribunal de cualquiera de ellos. Pero, incluso en este caso, parece adecuado que solo quepa una reconvención si la sociedad que presenta reconvención ha sido codemandada inicialmente. Solo así se preservaría la igualdad de armas: la sociedad polaca podría ser demandada ante los tribunales italianos y la sociedad polaca podría reconvenir en esos mismos tribunales.

19. La antítesis expuesta podría ser criticada por cierta contradicción, principalmente: se entiende que hay conexidad en el foro del litisconsorcio pasivo, pero no se entiende que hay conexidad en el foro de la reconvención. Sin dejar de ser cierto esto, hay dos matices diferenciales. Por un lado, el entramado societario debería poder invocarlo por conexidad la contraparte perjudicada por esa estructura, el trabajador, pero no la parte que se beneficia de ella. Por otro lado, en el foro de la reconvención no debe estar solo presente un requisito de conexidad objetiva, sino, también, de identidad subjetiva ${ }^{35}$. Ciertamente, además de un foro conexo, el de la reconvención es un foro dependiente de la delimitación de las partes litigantes. Y ello es lo que no concurre en el caso, no hay identidad real de partes en la reconvención; solo un juego artificioso de una cesión de créditos entre sociedades del mismo grupo para eludir la falta de identidad real de partes y sustituirla por una identidad meramente formal.

\section{Valoración}

20. Ante el silencio del Tribunal, conviene aclarar que el Reglamento "Bruselas I", y su actual versión refundida, no atribuyen un derecho a presentar reconvención. Solo facilitan la competencia judicial internacional cuando esta es posible. Y esa posibilidad depende de dos cuestiones previas obviadas en la Sentencia: la legitimación activa del demandante reconvencional por la ley del fondo y la admisibilidad procesal de la reconvención por la ley del foro.

A partir de aquí, la Sentencia tiene luces y sombras. Luces, por consolidar la competencia del juez inicial para una reconvención por razones de economía procesal, incluso cuando el demandante reconvencional sea una parte más fuerte jurídica y económicamente, como es un empleador. En su haber, también, exigir que la reconvención tenga un origen común a la demanda inicial, pues en este foro también persiste el objetivo de buscar resoluciones coherentes.

Entre las sombras, el Tribunal, al aplicar la doctrina general al caso concreto, legitima una situación abusiva. El demandante reconvencional está utilizando el entramado de sociedades del grupo para diseñar la reconvención y lo hace a través de una cesión de créditos que afecta a la posición procesal del demandado reconvencional. Esto resulta especialmente grave porque este demandado reconvencional no participa de dicha cesión (es un acto ajeno) y ni siquiera puede calcular sus efectos, al ser posterior a la interposición de la demanda inicial y vulnerar principios procesales básicos como la fijación de los hechos relevantes desde el momento de interposición de la demanda originaria.

${ }^{34}$ Vid. STJUE 22 mayo 2008, Glaxosmithkline, antes citada. Vid. M. Gardeñes Santiago, loc. cit., núm. V. Sobra la evolución en esta materia, vid. G. Palao Moreno, op. cit., p. 248.

${ }^{35}$ Cf. F. J. Garcimartín Alférez, Derecho Internacional Privado, $4^{\mathrm{a}}$ ed., Cizur Menor, Civitas/Thomson Reuters, 2017, p. 146. 
El Tribunal tampoco se plantea qué ocurriría si, al margen del caso, no existe ese origen común entre demanda inicial y reconvención. En principio, no habría competencia del juez inicial, pero solo se controlaría de oficio si están afectadas competencias exclusivas. De otro modo, deberá ser el demandado por reconvención quien o bien impugne la competencia por falta de origen común, o bien se someta tácitamente para esa reconvención. En el caso de un trabajador deberá ser informado de las consecuencias de aceptar la competencia para aquella reconvención sin un origen común a la demanda inicial. 